\title{
Three-dimensional pulsed continuous arterial spin labeling and intravoxel incoherent motion imaging of nasopharyngeal carcinoma: correlations with $\mathrm{Ki}-67$ proliferation status
}

\author{
Wenxiu $\mathbf{W u}^{1}$, Guihua Jiang ${ }^{2}$, Zhifeng $\mathrm{Xu}^{1}$, Ruoning Wang ${ }^{3}$, Aizhen Pan ${ }^{1}$, Mingyong Gao ${ }^{1}$, Tian Yu ${ }^{1}$, \\ Linwen Huang ${ }^{1}$, Qiang Quan ${ }^{4}$, Jin Li $^{5}$ \\ ${ }^{1}$ Department of Radiology, The First People's Hospital of Foshan, Foshan, China; ${ }^{2}$ Department of Medical Imaging, Guangdong Second Provincial \\ General Hospital, Guangzhou, China; ${ }^{3}$ Minimally Invasive Center, Tumor hospital, Sun Yat-Sen University, Guangzhou, China; ${ }^{4}$ Nasopharyngeal \\ Radiotherapy Department 2, The First People's Hospital of Foshan, Foshan, China; ${ }^{5}$ Pathology Department, The First People's Hospital of Foshan, \\ Foshan, China
}

Correspondence to: Guihua Jiang. Department of Medical Imaging, Guangdong Second Provincial General Hospital, Guangzhou, China. Email: jiangguihua1970@163.com.

Background: Recurrence and distant metastasis are still the main problems affecting the long-term prognosis of nasopharyngeal carcinoma (NPC) patients, and may be related to the Ki-67 proliferation status. We therefore explored the potential correlation between Ki-67 proliferation status in NPC with the parameters derived from two imaging techniques: three-dimensional pulsed continuous arterial spin labeling (3D pCASL) and intravoxel incoherent motion (IVIM).

Methods: Thirty-six patients with pathologically confirmed NPC were included, and the Ki-67 labeling index (LI) was measured by immunohistochemistry. All patients underwent plain and contrast-enhanced magnetic resonance imaging (MRI), IVIM, and 3D pCASL examination. The mean, maximum, and minimum of blood flow (BF), minimum of apparent diffusion coefficient (ADC), pure diffusion coefficient (D), pseudodiffusion coefficient $\left(\mathrm{D}^{*}\right)$, and perfusion fraction $(\mathrm{f})$ parameters were all measured, and Spearman's correlation analysis was performed to evaluate the relationships between these parameters and the Ki-67 LI. According to the Ki-67 values, the patients were divided into two groups: high $(>50 \%)$ and low $(\leq 50 \%)$. The rank-sum test (Mann-Whitney $\mathrm{U}$ test) was then used to compare the differences in quantitative parameters between the high and low Ki-67 groups.

Results: Ki-67 LI was positively correlated with $\mathrm{BF}_{\text {mean }}$ and $\mathrm{BF}_{\max }(\mathrm{r}=0.415$ and 0.425$) . \mathrm{D}_{\text {mean }}^{*}$ and $\mathrm{D}_{\text {min }}^{*}$ did have positive correlation with $\mathrm{Ki}-67$, but this was not significant $(\mathrm{P}=0.082$ and 0.072$) . \mathrm{BF}_{\max }$ was significantly different between the high and low Ki-67 groups ( $\mathrm{P}=0.028)$.

Conclusions: 3D pCASL and IVIM are noninvasive functional MR perfusion imaging techniques that can evaluate perfusion information and perfusion parameters. Our study suggests that $3 \mathrm{D}$ pCASL is more effective than IVIM for assessing the proliferation status of NPC, which is beneficial for evaluating the prognosis of patients. Furthermore, $\mathrm{BF}_{\max }$ is the best biomarker for distinguishing high from low Ki-67 levels.

Keywords: Spin labels; nasopharyngeal carcinoma (NPC); Ki-67 antigen; diffusion magnetic resonance imaging

Submitted Feb 25, 2020. Accepted for publication Nov 05, 2020.

doi: 10.21037/qims-20-349

View this article at: http://dx.doi.org/10.21037/qims-20-349 


\section{Introduction}

Nasopharyngeal carcinoma (NPC) is the most common malignant tumor of the head and neck in China. It displays regional aggregation, especially in southeast Asia and southern China, as well as in Chinese immigrants (1). With the application of intensity-modulated radiotherapy (IMRT) and neoadjuvant chemotherapy, the 5-year survival rate of NPC patients has gradually improved; however, recurrence and distant metastasis are still the main issues affecting the long-term prognosis of patients (2). A comprehensive assessment of tumor invasiveness prior to treatment can help predict tumor prognosis and tailor treatments for patients (3). The state of tumor proliferation is related to the biological behavior of the tumor, which is a reliable indicator of tumor invasiveness (3). Ki-67 is a nuclear protein which is only expressed in proliferating cells, and the Ki-67 labeling index (LI) therefore reflects tumor cell proliferation. Studies have confirmed that Ki-67 expression is closely related to the aggressiveness of breast cancer and lung cancer $(4,5)$, while other studies have also linked $\mathrm{Ki}-67$ expression to the staging and prognosis of NPC (6,7). Zhao et al. (6) found that Ki-67 expression in NPC is high, indicating poor prognosis. Several previous studies $(3,8)$ have suggested that the cutoff point of high $\mathrm{Ki}-67$ expression is $50 \%$, and $\mathrm{Ki}-67>50 \%$ indicates a worse prognosis. Therefore, Ki-67 expression can be a useful indicator to predict local recurrence, metastasis, and prognosis of NPC.

Currently, several magnetic resonance (MR) examination methods exist for the noninvasive assessment of tumor proliferation, such as apparent diffusion coefficient (ADC), diffusion-kurtosis imaging (DKI), dynamic contrast-enhanced (DCE), arterial spin labeling (ASL), and intravoxel incoherent motion (IVIM) (8-10). Qiu et al. (9) and Ma et al. (11) found that DCE-MR technology can accurately predict the expression of Ki-67 and reflect the degree of tumor proliferation. However, the biggest limitation of this technology is that contrast agent injection can result in renal function damage and fibrosis in patients with impaired renal function. Three-dimensional pulsed continuous arterial spin labeling (3D pCASL) technology, which can safely and noninvasively evaluate tissue perfusion information without a contrast agent, is thus predominantly used in the nervous system $(12,13)$. Zeng et al. (10) found that high cerebral blood flow (CBF) was correlated with high malignancy and a low survival rate in glioma patients. However, the application of ASL technology in NPC is still in its infancy $(14,15)$. Lin et al. $(14,15)$ found that ASL demonstrated utility for displaying the tumor tissue of NPC when the post-labeling delay time (PLD) was 1,025 ms. To the best of our knowledge, the relationship between the quantitative parameters derived from ASL and Ki-67 has not been reported in NPC. IVIM (16) can distinguish the diffusion movement of pure water molecules in tissues from capillary microcirculation perfusion without a contrast agent. It has been widely used in evaluating liver fibrosis $(17,18)$, staging (19), efficacy evaluation (20,21), differential diagnosis of fibrosis, and recurrence of NPC after radiotherapy (22). Studies on the correlation between IVIM and Ki-67 have been reported in breast cancer (23), sinonasal malignancies (8), and nude mouse models of NPC (24), but the relationship between the quantitative parameters of IVIM and Ki-67 in human NPC has not been examined. At present, some studies have compared and discussed the advantages of ASL and IVIM $(25,26)$. Shen et al. $(25)$ believed that IVIM could evaluate the markers of a preoperative grade of glioma, and could be used as a substitute for ASL in evaluating tumor perfusion. However, there is still a lack of relevant research reports on the correlation between relevant indicators of these two technologies and the Ki-67 LI. Accordingly, we hypothesized that the corresponding indicators of $3 \mathrm{D}$ pCASL and IVIM could accurately reflect Ki-67 levels and the proliferation of tumors, and noninvasively and comprehensively evaluate the heterogeneity and invasiveness of NPC.

In this study, IVIM and 3D pCASL were used to evaluate the diffusion and perfusion information of patients with NPC, and to analyze the potential correlation with the Ki67 LI. Both methods were used to predict the degree of proliferation and prognosis of NPC by noninvasive MR perfusion imaging in clinical practice, which is conducive to the formulation of clinical treatment plans and reducing the risk of recurrence and metastasis. These methods also had the distinct advantage of being applied even in patients with impaired renal function.

\section{Methods}

\section{Patients}

Fifty cases of NPC diagnosed by nasopharyngoscopy and pathology in our hospital from January to July 2019 were examined. They were all undifferentiated nonkeratinized carcinomas. The inclusion criteria were as 


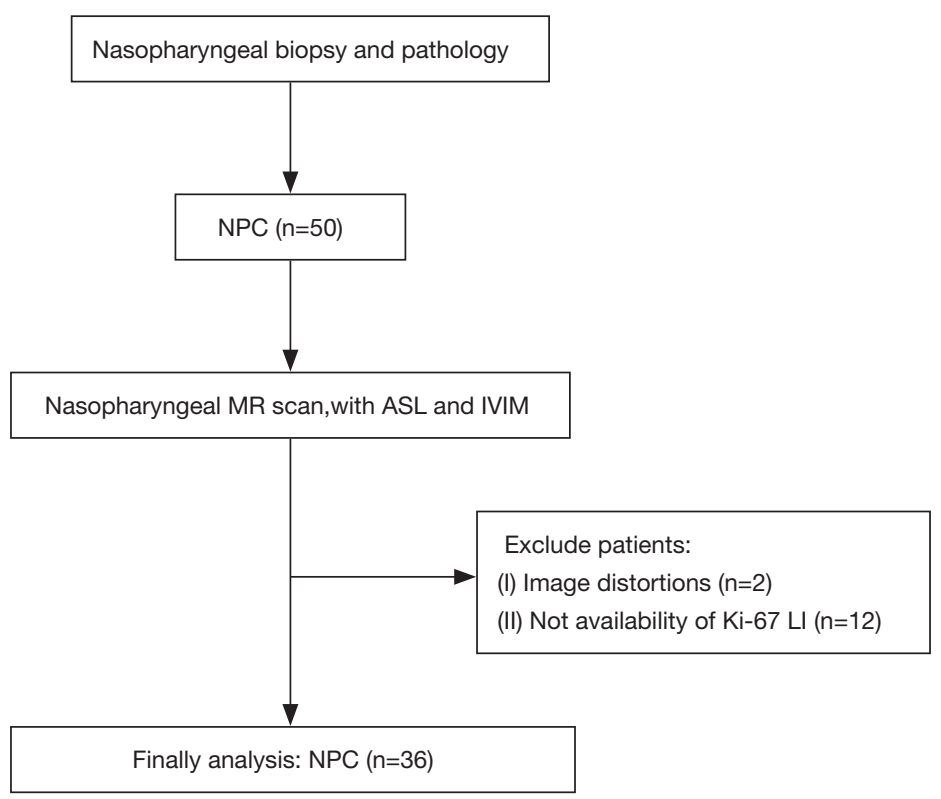

Figure 1 Flowchart depicting the patient selection process.

follows: (I) all patients were diagnosed for the first time and had not received any treatment (chemotherapy or chemoradiotherapy) before diagnosis; and (II) no contraindications were found upon MR examination. The exclusion criteria were as follows: (I) patients with NPC combined with other head and neck tumors, (II) patients with poor image quality after inclusion, (III) patients with intolerance of the MR scan, and (IV) patients without a Ki$67 \mathrm{LI}$. A flow chart depicting patient selection is shown in Figure 1. Finally, 36 newly diagnosed NPC patients were enrolled, including 28 males and 8 females (mean age $47.33 \pm 12.74$ years; range, $27-73$ years). According to the staging standard of the eighth edition of the American Joint Committee on Cancer (AJCC) guidelines, there were 0 patients in stage I, 10 patients in stage II, 9 patients in stage III, and 17 patients in stage IV. Most patients presented with a painless mass in the neck (15/36) and congestion/ blood in the nose (14/36) accompanied by tinnitus, headache, hearing loss. and other symptoms, with a history duration of 1-9 months. Seven patients (7/36) had a family history of cancer, and five had a family history of NPC. The prospective study was approved by the ethics committee of Foshan First People's Hospital, and all patients provided informed consent.

\section{MR techniques}

Examinations were performed with a $3.0 \mathrm{~T}$ magnetic resonance scanner (Discovery MR 750 w 3.0 T system, GE Healthcare Milwaukee, WI, USA) and an 8-channel head-and-neck combined coil (GE Healthcare). The contrast agent used for MRI examinations was gadolinium meglumine injection (Magnevist, Bayer Schering Pharma, Germany).

(I) The conventional MR scanning included the following T1-weighted fluid-attenuated inversion recovery (FLAIR T1WI) sequence: time of repeation $(\mathrm{TR}) /$ time of echo $(\mathrm{TE})=657 \mathrm{~ms} / 24 \mathrm{~ms}$, time of inversion $(\mathrm{TI})=780 \mathrm{~ms}$; a fat-saturated $\mathrm{T} 2 \mathrm{WI}$ fast spin echo (FSE)-based sequence: TR/TE $=5,114 \mathrm{~ms} / 110 \mathrm{~ms}$, number of excitations (NEX) $=2.0$, field of view $(\mathrm{FOV})=240 \mathrm{~mm} \times 240 \mathrm{~mm}$, matrix $=288 \times 224$, section thickness $/ \mathrm{gap}=5 \mathrm{~mm} / 1 \mathrm{~mm}$, layer number $=36$; and coronal T2WI-FS plain scanning: $\mathrm{TR} / \mathrm{TE}=2,250 \mathrm{~ms} / 64 \mathrm{~ms}$.

(II) IVIM-DWI: multiple B-DWI (MB-DWI) with 13 b-values $(0,10,20,40,60,100,120,160,200$, $400,600,800$, and $1,000 \mathrm{~s} / \mathrm{mm}^{2}$ ) were applied using the follwoing single-shot spin echo echoplanar imaging sequence: $\mathrm{TR} / \mathrm{TE}=3,685 \mathrm{~ms} / 43 \mathrm{~ms}$, NEX $=2.0, \mathrm{FOV}=240 \mathrm{~mm} \times 240 \mathrm{~mm}$, matrix $=160 \times 160$, section thickness/gap $=5 \mathrm{~mm} / 0 \mathrm{~mm}$, layer number $=22$, scanning time $=3 \min 30 \mathrm{~s}$.

(III) 3 D pCASL: a pseudo-continuous ASL sequence with a $3 \mathrm{D}$ FSE spiral acquisition was performed with the following parameters: 
$\mathrm{TR} / \mathrm{TE}=4,295 \mathrm{~ms} / 11.5 \mathrm{~ms}, \mathrm{NEX}=3.0$, section thickness $/$ gap $=3 \mathrm{~mm} / 0 \mathrm{~mm}$, layer number $=30$, FOV $=220 \mathrm{~mm} \times 220 \mathrm{~mm}$, matrix $=288 \times 192, \mathrm{PLD}$ time $=1,025 \mathrm{~ms}(1.0 \mathrm{~s})$, scanning time $=4 \min 10 \mathrm{~s}$.

(IV) Axial T2WI-FS: this was performed with the scanning range and positioning line consistent with those of ASL, and the following additional parameters: $\mathrm{TR} / \mathrm{TE}=3,000 \mathrm{~ms} / 68 \mathrm{~ms}$.

(V) Conventional contrast-enhanced scanning: after injection of the contrast agent at a rate of $0.2 \mathrm{~mL} / \mathrm{kg}$ and $2.0 \mathrm{~ms}$, cross-sectional, coronal, and sagittal T1WI-FS were performed with the following parameters: $\mathrm{TR} / \mathrm{TE}=655 \mathrm{~ms} / 9.5 \mathrm{~ms}$.

\section{MR image post-processing}

The MB-DWI and ASL raw data obtained from the scans were transferred to GE-AW 4.6 workstation software for post-processing. Based on the IVIM theory, the biexponential model can be expressed by the following equation, as described by Le Bihan et al. (16):

$$
S_{b} / S_{0}=(1-f) \cdot \exp (-b \cdot D)+j \cdot \exp \left[-b \cdot\left(D+D^{*}\right)\right]
$$

where $S_{0}$ is the signal intensity in the pixel without diffusion gradient, and $S_{b}$ is the signal intensity in the pixel with diffusion gradient $\mathrm{b}$. Three parameters, $\mathrm{D}, \mathrm{D}^{*}$ and $\mathrm{f}$, can be derived from IVIM by fitting the MR signal acquired at 13 b-values ( $\mathrm{b}=0,10,20,40,60,100,120,160,200,400$, 600,800 , and $1,000 \mathrm{~s} / \mathrm{mm}^{2}$ ) to a bi-exponential model. $\mathrm{D}$ represents a true diffusion coefficient related to pure molecular diffusion, $\mathrm{D}^{*}$ represents the pseudodiffusion coefficient indicating incoherent microcirculation or perfusion related diffusion, and $\mathrm{f}$ represents the fractional perfusion as reflected by the fraction of diffusion linked to microcirculation.

ASL data were post-processed to obtain tumor blood flow (BF), using the following equation (27):

$$
\begin{aligned}
& B F=\left[6,000 \cdot \lambda \cdot\left(S I_{\text {control }}-S I_{\text {label }}\right) \cdot \exp \left(P L D / T_{1, \text { blood }}\right)\right] / \\
& \left\{2 \cdot \alpha \cdot T_{1, \text { blood }} \cdot S L_{P D} \cdot\left[1-\exp \left(\tau / T_{1, \text { blood }}\right)\right]\right\}[\mathrm{mL} / 100 \mathrm{~g} / \mathrm{min}]
\end{aligned}
$$

where BF is blood flow, $\alpha$ indicates the labeling efficiency, $\mathrm{T} 1$, blood is the longitudinal relaxation time of blood in seconds, $\mathrm{SI}_{\mathrm{PD}}$ is the signal intensity of a proton densityweighted image, $\tau$ is the label duration, $\lambda$ is the blood partition coefficient in $\mathrm{mL} / \mathrm{g}$, and $\mathrm{SI}_{\text {control }}$ and $\mathrm{SI}_{\text {label }}$ are the time averaged signal intensities in the control and label images, respectively. PLD represents the post-la beling delay time. A factor of 6,000 converts the unit from $\mathrm{mL} / \mathrm{g} / \mathrm{s}$ to $\mathrm{mL} / 100 \mathrm{~g} / \mathrm{min}$, which is customary in the physiological literature.

Combined with enhanced images, BF, standard ADC, and IVIM (D, $D^{*}$, and $\mathrm{f}$ ) parameters were measured independently by two radiologists (readers 1 and 2 with 7 years of experience each in head and neck imaging) who were blinded to clinical and histopathological data. Five regions of interest (ROIs) were placed on the tumors on the corresponding parameter maps, which were proposed in a previous study (8). We selected the largest area of the tumor, including the entire tumor, and calculated the $\mathrm{BF}_{\text {mean }}, \mathrm{ADC}_{\text {mean }}, \mathrm{D}_{\text {mean }}, \mathrm{D}_{\text {mean }}^{*}$, and $\mathrm{f}_{\text {mean }}$ values. On the ASL image, the maximum and minimum value regions of the image were selected to measure the $\mathrm{BF}_{\max }$ and $\mathrm{BF}_{\min }$. The ROI was placed at the minimum value regions of the standard $\mathrm{ADC}$ position calculated as the $\mathrm{ADC}_{\min }$ value, and the corresponding regions of the IVIM value were recorded as $\mathrm{D}_{\text {min }}, \mathrm{D}_{\text {min }}^{*}$, and $\mathrm{f}_{\min }$. The maximum and minimum value regions of the ROI area were $40-50 \mathrm{~mm}^{2}$. All of the above values were measured three times to obtain the average.

\section{Immunobistochemistry and Ki-67 labeling index}

Routine paraffin sections $(4 \mathrm{~mm})$ from 36 cases of NPC were prepared on polylysine-coated slides and incubated at $70^{\circ} \mathrm{C}$ for 24 hours for use. The sections were dewaxed and hydrated, and the antigen was repaired using the thylene diamine tetra acetic acid (EDTA) method. Immunohistochemistry of Ki-67 was performed in accordance with the 2-step method. The main reagents were mouse anti-human CD31 monoclonal antibody, concentrated mouse anti-human Ki-67 monoclonal antibody, a hypersensitivity kit, and a DAB kit, all purchased from Fuzhou Maixin Biotechnology Company (China). Two senior pathologists who were double-blinded to the experiment conditions examined the sections. Five different fields of view were randomly selected under a high-power microscope, and for each field, 200 tumor cells were counted.

\section{Statistical analysis}

SPSS 20.0 statistical software (IBM, NY, USA) was used to analyze the data and compare the correlation between the $\mathrm{BF}, \mathrm{ADC}, \mathrm{D}, \mathrm{D}^{*}$, and $\mathrm{f}$ parameters and Ki-67. To determine the correlations between $\mathrm{D}_{\text {mean }}^{*}, \mathrm{f}_{\text {mean }}$, and $\mathrm{BF}_{\text {mean }}$, Spearman's correlation analysis was performed with an $\mathrm{r}$ value of 
Table 1 Correlations between quantitative MR parameters (ASL, ADC, D, D*, and f) and the Ki-67 labeling index in NPC

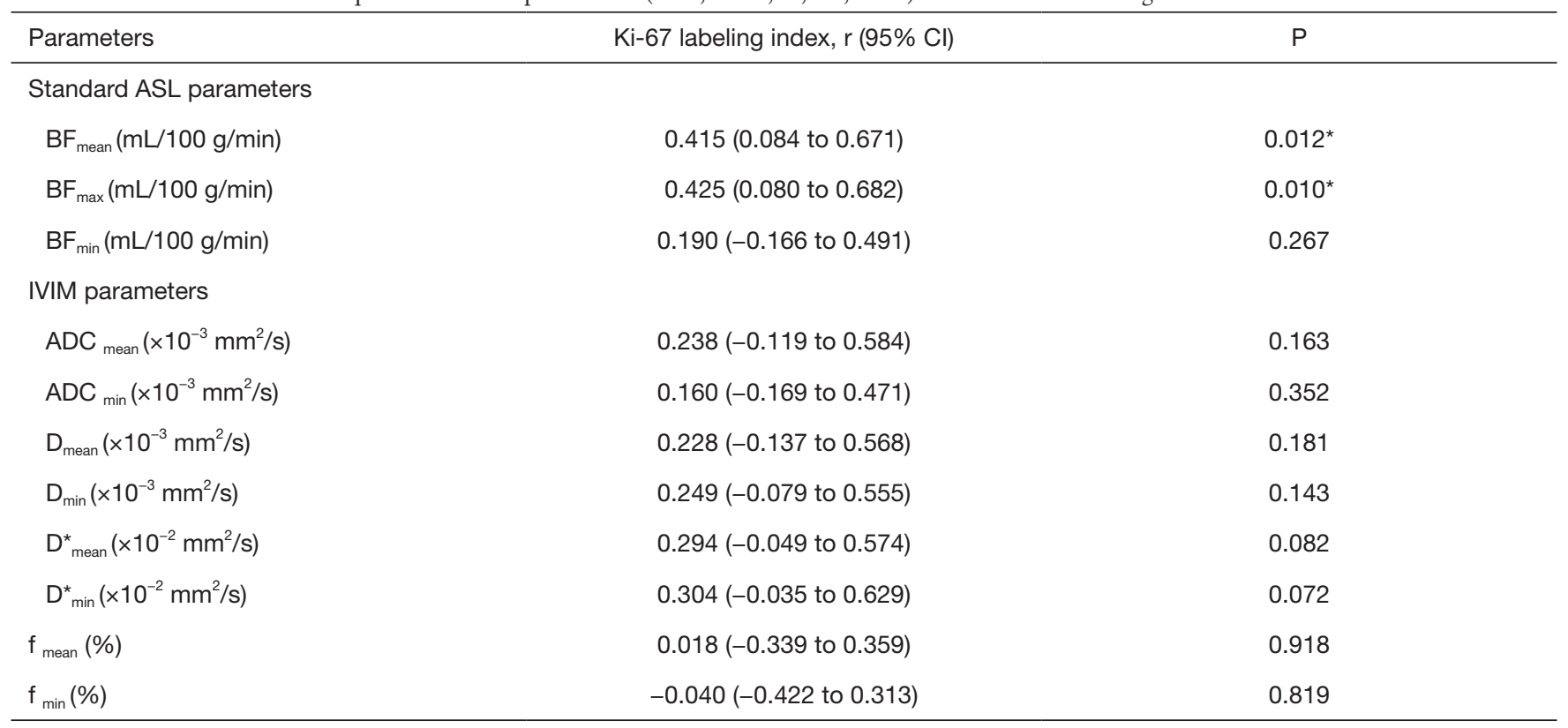

*, P<0.05. NPC, nasopharyngeal carcinoma; $r$, correlation coefficient; 95\% Cl, 95\% confidence intervals; ASL, arterial spin labeling; IVIM, intravoxel incoherent motion; $\mathrm{BF}$, blood flow; $\mathrm{BF}_{\text {mean }}$, mean $\mathrm{BF}$; $\mathrm{BF}_{\max }$, maximum $\mathrm{BF}$; $\mathrm{BF}_{\min }$, minimum $\mathrm{BF}$; $\mathrm{ADC}$, apparent diffusion coefficient; $A D C_{\text {mean }}$, mean $A D C ; A D C_{\text {min }}$, the minimum $A D C ; D$, pure diffusion coefficient; $D_{\text {mean }}$, mean $D ; D_{\text {min }}$, the minimum $A D C$ corresponding $D ; D^{*}$, pseudo-diffusion coefficient; $D^{*}{ }_{\text {mean }}$, mean $D^{*} ; D^{*}{ }_{\text {min }}$, the minimum ADC corresponding $D^{*} ; f$, perfusion fraction; $f_{\text {mean }}, m$ mean $f ; f_{\text {min }}$, the minimum ADC corresponding $f$.

0.71-1.00 being considered highly correlated, $0.40-0.70$ being moderately correlated, $\leq 0.40$ being poorly correlated. A $\mathrm{P}$ value $<0.05$ was considered statistically significant.

The tumors were divided into a low-expression group $(\leq 50 \%)$ and a high-expression group (>50\%), with Ki67 of $50 \%$ as the cutoff point, and the parameters of the high-level group were expressed as mean \pm standard deviation(SD). The rank-sum test (Mann-Whitney U test) was used to compare the differences of all the BF, ADC, D, $\mathrm{D}^{*}$, $\mathrm{f}$ values between the $2 \mathrm{Ki}-67$ groups, and the receiver operating characteristic (ROC) curve was used to evaluate the diagnostic efficacy of differential quantitative parameters in the identification of the high- and low-expression groups. A $\mathrm{P}$ value $<0.05$ was considered statistically significant.

\section{Results}

Correlation between quantitative parameters of $3 D$ pCASL, IVIM, and Ki-67 in NPC: the BF $F_{\text {mean }}$ and $B F_{\text {max }}$ were positively correlated with Ki-67

The Ki-67 values ranged from $10 \%$ to $90 \%$, with an average of $44.22 \%$. The correlation between quantitative MR parameters (BF, ADC, D, D*, and f) and Ki-67 in NPC are summarized in Table 1 . The $\mathrm{BF}_{\text {mean }}$ and $\mathrm{BF}_{\text {max }}$ were positively correlated with $\mathrm{Ki}-67$, and the correlation coefficients $\mathrm{r}$ were 0.415 and $0.425(\mathrm{P}<0.05)$, respectively (Figure $2 A, B)$.

$\mathrm{D}^{*}{ }_{\text {mean }}$ and $\mathrm{D}^{*}{ }_{\text {min }}$ were not significantly correlated with Ki-67, and the $\mathrm{P}$ values were 0.082 and 0.072 , respectively, indicating a non-significant positive correlation with $\mathrm{Ki}$ 67 (Figure $2 C, D) . \mathrm{BF}_{\text {min }}, \mathrm{ADC}_{\text {mean }}, \mathrm{ADC}_{\text {min }}, \mathrm{D}_{\text {mean }}, \mathrm{D}_{\text {min }}$, $\mathrm{f}_{\text {mean }}$, and $\mathrm{f}_{\text {min }}$ were not significantly correlated with Ki-67 $(\mathrm{P}>0.05$; Figure $2 E, F)$. Meanwhile, there were no significant correlations between $\mathrm{D}_{\text {mean }}^{*}, \mathrm{f}_{\text {mean }}$, and $\mathrm{BF}_{\text {mean. }}$.

\section{Differences in the quantitative parameters of IVIM and $3 D$ pCASL between the two groups based on Ki-67 values in NPC}

Using a $50 \%$ cutoff, 16 tumors (44.4\%) were categorized as high $\mathrm{Ki}-67$, and the remaining 20 (55.6\%) were categorized as low Ki-67. Table 2 presents the results of the comparative analyses of $\mathrm{BF}, \mathrm{ADC}, \mathrm{D}, \mathrm{D}^{*}$, and $\mathrm{f}$ between low and high $\mathrm{Ki}-67 \mathrm{NPC}$ cases. The $\mathrm{BF}_{\max }$ value was significantly higher in cases with a high $\mathrm{Ki}-67$ status than in those with a low $\mathrm{Ki}-67$ status $(\mathrm{P}=0.028)$ (Figures 3,4). Contrastingly, there was no significant difference in IVIM parameters between 

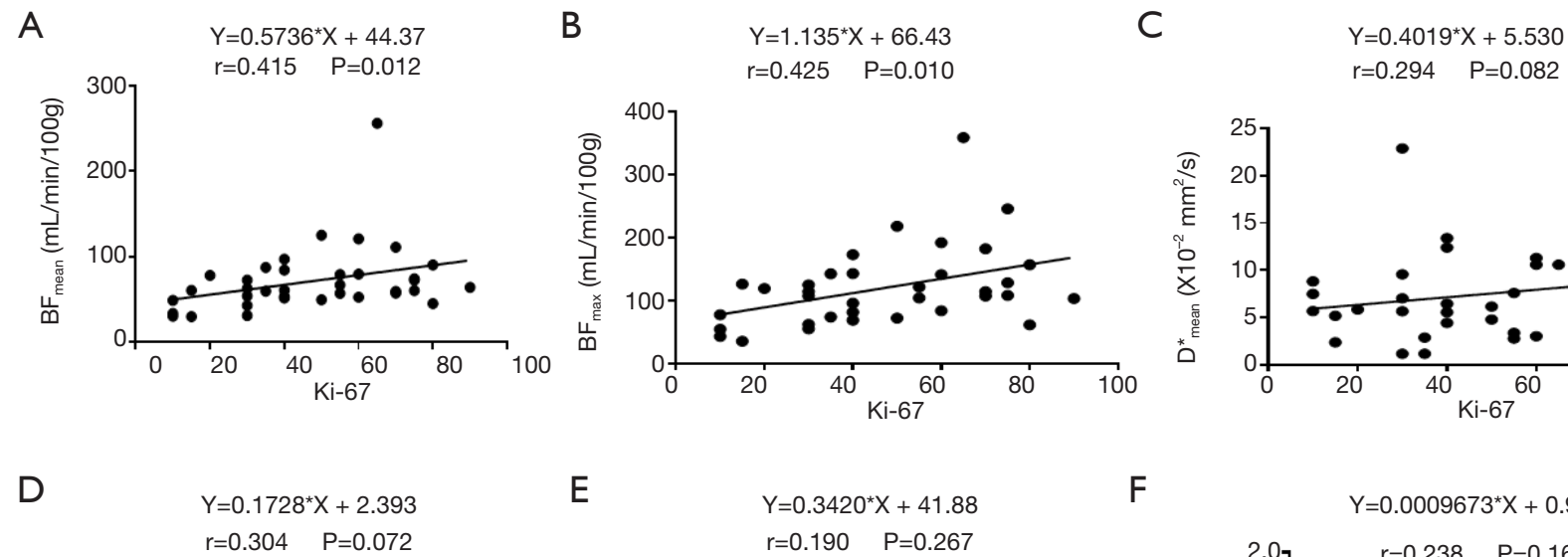

$\mathrm{E}$
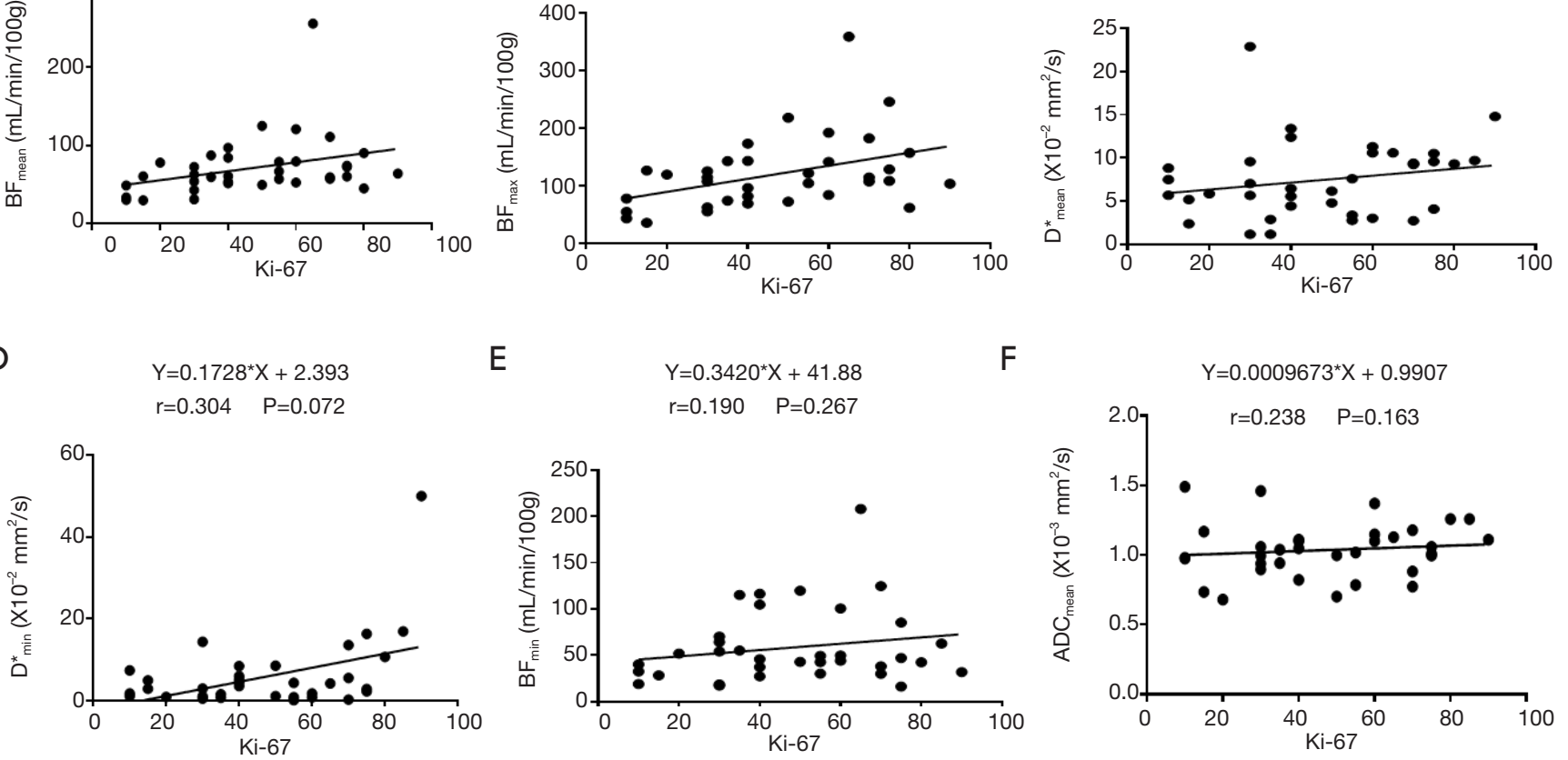

$\mathrm{F}$

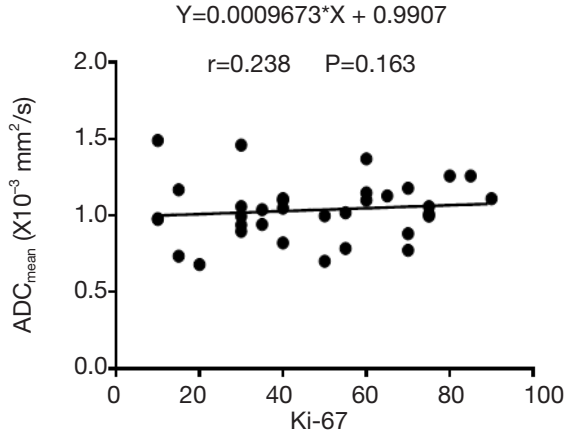

Figure 2 Correlations between the quantitative MR parameters (ASL and IVIM) and the Ki-67 labeling index in NPC. (A) The $\mathrm{BF}_{\text {mean }}$ were positively correlated with $\mathrm{Ki}-67$ and the correlation coefficients $r$ were 0.415 . (B) $\mathrm{BF}_{\max }$, were positively correlated with Ki-67 and the correlation coefficients $\mathrm{r}$ were $0.425(\mathrm{P}<0.05)$. (C) $\mathrm{D}^{*}{ }_{\text {mean }}$ were not significantly correlated with Ki-67, as the $\mathrm{P}$ values were 0.082 . (D) $\mathrm{D}^{*}{ }_{\text {min }}$ were not significantly correlated with Ki-67, as the $\mathrm{P}$ values were 0.072 , but a positively correlation with Ki-67 was nonetheless observed. (E) $\mathrm{BF}_{\text {min }}$ were not significantly correlated with Ki-67 (P>0.05). (F) $\mathrm{ADC}_{\text {mean }}$ were not significantly correlated with Ki-67 (P>0.05). NPC, nasopharyngeal carcinoma; ASL, arterial spin labeling; IVIM, intravoxel incoherent motion; $\mathrm{BF}$, blood flow; $\mathrm{BF}_{\text {mean }}$, mean $\mathrm{BF}$; $\mathrm{BF}_{\max }$, maximum $\mathrm{BF} ; \mathrm{BF}_{\text {min }}$, minimum $\mathrm{BF} ; \mathrm{ADC}$, apparent diffusion coefficient; $\mathrm{ADC}_{\text {mean }}$, mean $\mathrm{ADC}$; $\mathrm{D}^{*}$, pseudo diffusion coefficient; $\mathrm{D}^{*}$ mean mean $\mathrm{D}^{*} ; \mathrm{D}_{\text {min }}^{*}$, the minimum $\mathrm{ADC}$ corresponding $\mathrm{D}^{*}$.

the 2 groups. The $\mathrm{BF}_{\max }$ had the highest area under the curve (AUC) value of 0.714 , and the cutoff value, sensitivity, and specificity was $82.736 \mathrm{~mL} / 100 \mathrm{~g} / \mathrm{min}, 93.8 \%$, and $50 \%$, respectively (Figure 5).

\section{Discussion}

In this study, we explored the correlations between $\mathrm{BF}$ parameters derived from $3 \mathrm{D}$ pCASL and $\mathrm{ADC}, \mathrm{D}, \mathrm{D}^{*}$, and $\mathrm{f}$ derived from IVIM with the Ki-67 proliferation status in NPC before any treatment. The Ki-67 proliferation status was assessed predominantly by the pathological analysis of biopsy tissue. $\mathrm{BF}_{\text {mean }}$ and $\mathrm{BF}_{\text {max }}$ were positively correlated with $\mathrm{Ki}-67$. However, the ADC, D, and f values were not significantly correlated with the Ki-67 values; $\mathrm{D}^{\text {* }}$ did show a non-significant positive correlation with Ki-67, indicating that the perfusion parameters of ASL were more beneficial than IVIM for assessing the proliferation status of NPC. The $\mathrm{BF}_{\text {max }}$ of the high Ki-67 group was significantly higher than that of the low Ki-67 group, and no significant difference was found in IVIM parameters, indicating that $\mathrm{BF}_{\max }$ was the most significant biomarker for distinguishing high and low Ki-67 levels.

Our results showed that $\mathrm{BF}_{\text {mean }}$ and $\mathrm{BF}_{\text {max }}$ were positively correlated with Ki-67 in NPC. In previous studies, ASL was an effective perfusion index to evaluate tumor angiogenesis and glioma grade $(10,13,28)$, head and neck squamous cell carcinoma (HNSCC), and renal masses (29-31). Fujima et al. (29) found in a study of HNSCC that tumor BF (TBF) measurement by pCASL was feasible in patients. Shen et al. (25) studied 52 cases of glioma by ASL and found that the BF value could distinguish between grade II and grade III gliomas, and higher grade gliomas had a higher $\mathrm{BF}$ value, demonstrating that $\mathrm{BF}$ can indicate the grade 
Table 2 Comparison of ASL, ADC, D, D*, and f values of NPC with low and high Ki-67 statuses (mean \pm SD)

\begin{tabular}{|c|c|c|c|}
\hline Parameters & Low Ki-67 status $(n=20)$ & High Ki-67 status $(n=16)$ & $\mathrm{P}$ \\
\hline $\mathrm{BF}_{\text {mean }}(\mathrm{mL} / 100 \mathrm{~g} / \mathrm{min})$ & $61.56 \pm 25.03$ & $84.43 \pm 50.21$ & 0.058 \\
\hline $\mathrm{BF}_{\max }(\mathrm{mL} / 100 \mathrm{~g} / \mathrm{min})$ & $100.51 \pm 47.33$ & $145.48 \pm 72.44$ & $0.028^{*}$ \\
\hline $\mathrm{BF}_{\min }(\mathrm{mL} / 100 \mathrm{~g} / \mathrm{min}$ & $55.13 \pm 34.71$ & $62.59 \pm 47.98$ & 0.694 \\
\hline$A D C_{\text {mean }}\left(\times 10^{-3} \mathrm{~mm}^{2} / \mathrm{s}\right)$ & $0.98 \pm 0.18$ & $1.07 \pm 0.16$ & 0.149 \\
\hline $\mathrm{ADC}_{\min }\left(\times 10^{-3} \mathrm{~mm}^{2} / \mathrm{s}\right)$ & $0.67 \pm 0.17$ & $0.72 \pm 0.17$ & 0.479 \\
\hline $\mathrm{D}_{\text {mean }}\left(\times 10^{-3} \mathrm{~mm}^{2} / \mathrm{s}\right)$ & $0.78 \pm 0.14$ & $0.87 \pm 0.15$ & 0.236 \\
\hline $\mathrm{D}_{\min }\left(\times 10^{-3} \mathrm{~mm}^{2} / \mathrm{s}\right)$ & $0.56 \pm 0.14$ & $0.64 \pm 0.18$ & 0.290 \\
\hline$f_{\text {mean }}(\%)$ & $0.25 \pm 0.16$ & $0.29 \pm 0.25$ & 0.789 \\
\hline$f_{\min }(\%)$ & $0.28 \pm 0.19$ & $0.28 \pm 0.27$ & 0.694 \\
\hline
\end{tabular}

*, $\mathrm{P}<0.05$. NPC, nasopharyngeal carcinoma; ASL, arterial spin labeling; IVIM, intravoxel incoherent motion; SD, standard deviation; BF, blood flow; $\mathrm{BF}_{\text {mean }}$, mean $\mathrm{BF} ; \mathrm{BF}_{\max }$, maximum $\mathrm{BF} ; \mathrm{BF}_{\text {min }}$, minimum $\mathrm{BF} ; \mathrm{ADC}$, apparent diffusion coefficient; $\mathrm{ADC} \mathrm{C}_{\text {mean }}, \mathrm{mean}^{\mathrm{ADC}} \mathrm{ADC}$ min, the minimum $A D C$; $D$, pure diffusion coefficient; $D_{\text {mean }}$, mean $D ; D_{\text {min }}$, the minimum $A D C$ corresponding $D ; D^{*}$, pseudo-diffusion coefficient; $D^{*}{ }_{\text {mean }}$, mean $D^{*} ; D^{*}{ }_{\text {min }}$, the minimum $A D C$ corresponding $D^{*} ; f$, perfusion fraction; $f_{\text {mean }}$, mean $f ; f_{\text {min }}$, the minimum $A D C$ corresponding $f$.

of tumors and may be related to tumor proliferation. It is also feasible to evaluate the perfusion of NPC (15). In this study, $\mathrm{BF}_{\text {mean }}$ represented the average $\mathrm{BF}$ of the whole tumor, whereas $\mathrm{BF}_{\max }$ represented the highest blood flow in NPC. A higher $\mathrm{BF}_{\max }$ can indicate local NPC tissue blood vessels growing in quantity. $\mathrm{Ki}-67$ is an effective indicator of tumor proliferation, invasion, and prognosis (4-7). A higher Ki-67 level means faster proliferation of cells in NPC, which requires a more abundant blood supply. In this study, BF was positively correlated with Ki-67 in NPC. This result is also consistent with a previous study (10), in which the $\mathrm{CBF}_{\text {max }}$ of high-grade glioma was significantly higher than that of low-grade glioma, and where the larger the $\mathrm{CBF}_{\text {max }}$ was, the more malignant the tumor and the lower the survival rate. However, Zeng et al. (10) found that in glioblastoma, $\mathrm{CBF}_{\max }$ and the Ki-67 index were moderately negatively correlated, and lower $\mathrm{rCBF}_{\text {max }}$ was associated with worse overall survival (OS). The underlying pathological mechanisms are still unknown. Evans et al. (32) and Mashiko et al. (33) found that higher grade gliomas were associated with more hypoxia. The $3 \mathrm{D}$ pCASL parameter may be used to indicate the proliferation status of NPC, but the pathological types of different tumors are somewhat different.
This study found that the perfusion microcirculation coefficient $\mathrm{D}^{*}$ derived from IVIM was non-significantly correlated with $\mathrm{Ki}-67$. The ADC values obtained from standard DWI are useful imaging indicators for the clinical prediction of tumor proliferation status $(34,35)$. In our study, the use of the double exponential model IVIM scanning and the $0-1,000 \mathrm{~s} / \mathrm{mm}^{2} 13 \mathrm{~b}$ value, yielded information on the diffusion and movement of water molecules, and blood capillary microcirculation perfusion. In this study, $\mathrm{D}^{*}{ }_{\min }$ was the $\mathrm{D}^{*}$ values corresponding to the minimum ADC region. The minimum ADC region is the area where tumor cells are dense, which requires more abundant microcirculation. $\mathrm{D}^{*}{ }_{\min }$ was also increased, but the correlation coefficient between the $\mathrm{D}^{*}$ value and Ki-67 was not significant $(\mathrm{P}=0.072,0.082)$, which may be related to the small number of cases. In previous studies on sinonasal malignancy (8) and a nude mouse model of NPC (24), the Ki-67 value was found to have no correlation with $\mathrm{D}^{*}$. In the author's opinion, the probable reasons might have been the low signal-to-noise ratio and the relatively poor measurement reproducibility of $\mathrm{D}^{*}$ (36). In order to improve the measurement reproducibility of $\mathrm{D}^{*}$ in our study, we drew ROIs on ADC images combined with enhanced scanning, and performed amplification processing 

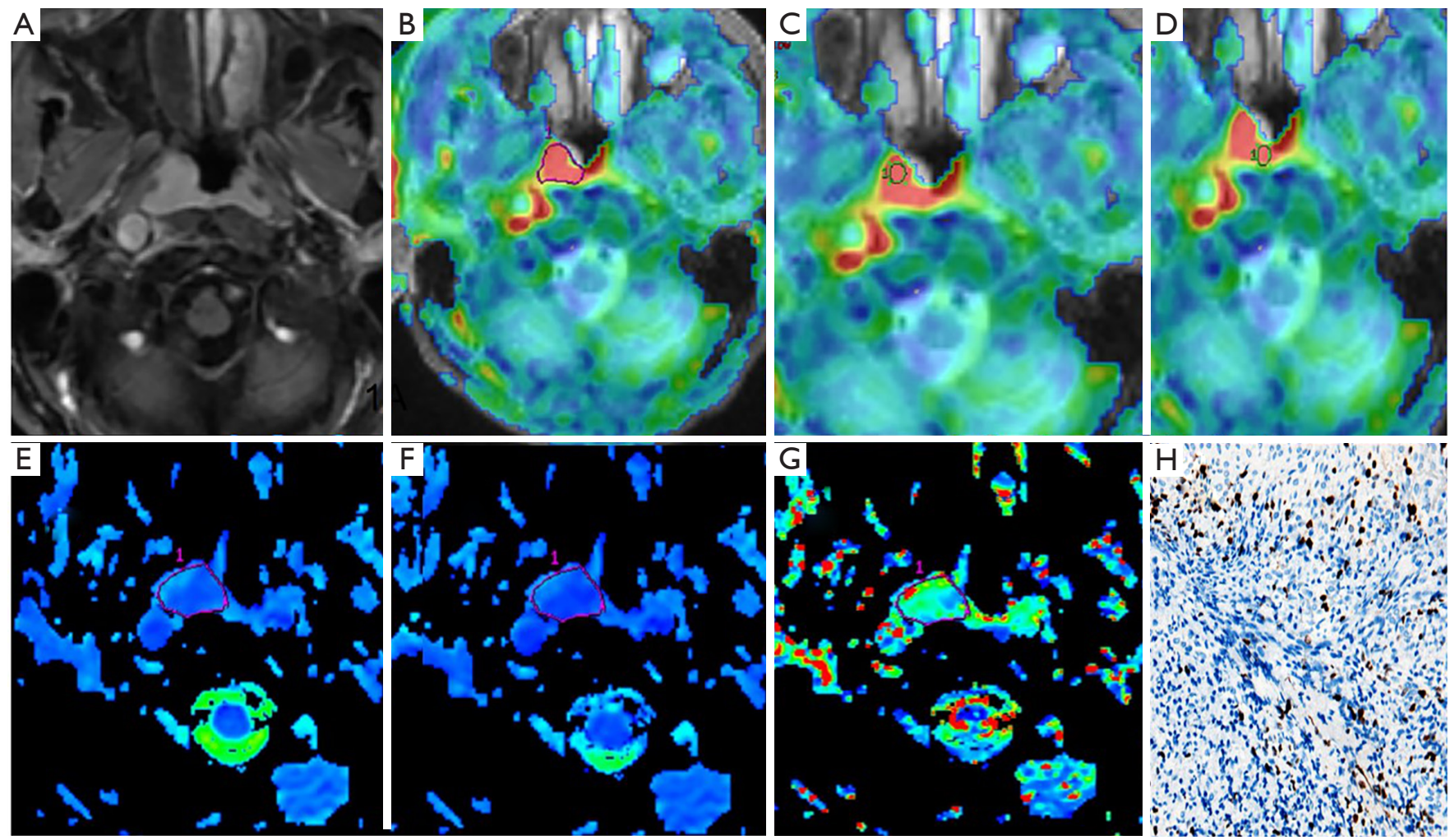

Figure 3 A 66-year-old male patient with NPC. (A) The right nasopharyngeal wall of T1WI was significantly thickened. (B) The lesion of BF was uniformly perfused, FST2WI/ASL fusion improved the lesion anatomical structure display, and the $\mathrm{BF}_{\text {mean }} \mathrm{value} \mathrm{was} 96.292 \mathrm{~mL} /$ $100 \mathrm{~g} / \mathrm{min}$. (C) $\mathrm{The} \mathrm{BF}_{\max }$ value of the lesion was $132.17 \mathrm{~mL} / 100 \mathrm{~g} / \mathrm{min}$. (D) The $\mathrm{BF}_{\min }$ value of the lesion was $90.875 \mathrm{~mL} / 100 \mathrm{~g} / \mathrm{min}$. (E) $\mathrm{ADC}_{\text {mean }}$ was $1.11 \times 10^{-3} \mathrm{~mm}^{2} / \mathrm{s}$. (F) The $\mathrm{D}_{\text {mean }}$ value was $0.891 \times 10^{-3} \mathrm{~mm}^{2} / \mathrm{s}$. (G) The $\mathrm{D}_{\text {mean }}^{*}$ value was $4.46 \times 10^{-2} \mathrm{~mm} / \mathrm{s}$. $(\mathrm{H}) \mathrm{Low} \mathrm{Ki}-67$ expression of $10 \%$ (IHC, $\times 400$, EnVision). NPC, nasopharyngeal carcinoma; $\mathrm{BF}$, blood flow; $\mathrm{BF}_{\text {mean }}$, mean $\mathrm{BF}$, $\mathrm{BF}_{\text {max }}$, maximum $\mathrm{BF}$; $\mathrm{BF}_{\text {min }}$, minimum $\mathrm{BF}$; $\mathrm{ADC}$, apparent diffusion coefficient; $\mathrm{ADC}_{\text {mean }}$, mean $\mathrm{ADC} ; \mathrm{D}_{\text {mean }}$, mean $\mathrm{D} ; \mathrm{D}^{*}$, pseudo-diffusion coefficient; $\mathrm{D}^{*}{ }_{\text {mean }}, \mathrm{mean}^{*}$.

of NPC tissues, so as to obtain more accurate $\mathrm{D}^{*}$ values. Moreover, while $\mathrm{D}^{*}$ is associated with Ki-67 in human NPC, this may be different from sinonasal malignancy and NPC in nude mice due to species differences.

In this study, no correlation was found between $\mathrm{Ki}$ 67 values and ADC, D, and f. Molinari et al. (37) found that the ADC value was also not significantly correlated with Ki-67 in breast cancer. However, Xiao et al. (8) found that the $\mathrm{Ki}-67$ value in malignant sinonasal tumors was negatively correlated with ADC and D, but positively correlated with the f value. They believed that ADC and the pure molecule diffusion coefficient $\mathrm{D}$ decreased due to high Ki-67 expression, dense cells, and limited diffusion of water molecules, whereas the microcirculation perfusion score $\mathrm{f}$ increased. Although $\mathrm{D}^{*}$, $\mathrm{f}$, and $\mathrm{BF}$ all reflect microcirculation, no correlation was found between them in our study. These results are inconsistent with previous studies, which may be related to the differences between tumor types, and the small number of cases in this study.

In addition, we found that the $\mathrm{BF}_{\text {max }}$ of the high $\mathrm{Ki}-67$ group with NPC was significantly higher than that of the low $\mathrm{Ki}-67$ group, and the cutoff point of $\mathrm{BF}_{\max }$ was found to be $82.44 \mathrm{~mL} / 100 \mathrm{~g} / \mathrm{min}$. However, there were no significant differences between the two groups in the quantitative parameters ADC, $D, D^{*}$, and $\mathrm{f}$. In this study, the cutoff point of $\mathrm{Ki}-67$ in the high- and low-grade groups was $50 \%$, and the cutoff point of $\mathrm{Ki}-67$ in the high and low grade groups was different for tumors in different studies. Valente et al. (38) reproted that a breast cancer Ki- 67 value $\geq 20 \%$ indicated high Ki-67 expression, where the lower the ADC was, the higher the Ki-67 proliferation and the stronger the invasion. In cases of sinonasal malignancies, multiple studies $(3,8,39)$ have suggested that the cutoff point of high Ki67 expression is $50 \%$, where $\mathrm{Ki}-67>50 \%$ indicates a worse 

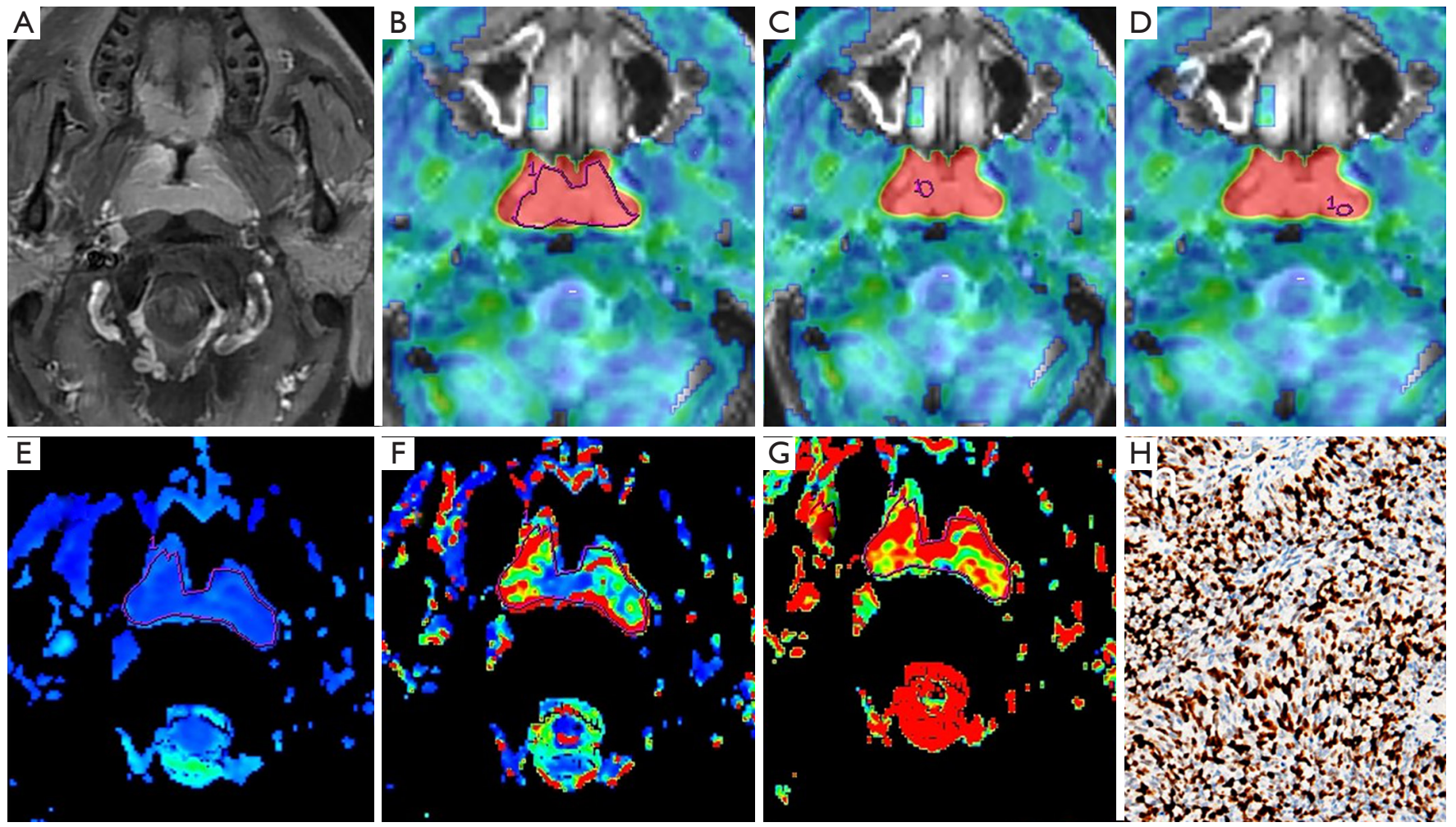

Figure 4 A 38-year-old male patient with NPC. (A) Enhanced T1WI showed nasopharyngeal soft tissue symmetry thickening. (B) FST2WI/ASL fusion images showed obvious hyperperfusion of BF lesions, with a $\mathrm{BF}_{\text {mean }}$ value of $256.39 \mathrm{~mL} / 100 \mathrm{~g} / \mathrm{min}$. $(\mathrm{C}) \mathrm{The}_{\mathrm{BF}}$ max $\mathrm{value}_{\mathrm{of}}$ the lesion was $358.53 \mathrm{~mL} / 100 \mathrm{~g} / \mathrm{min}$. (D) $\mathrm{BF}_{\min }$ of the lesion was $207.92 \mathrm{~mL} / 100 \mathrm{~g} / \mathrm{min}$. (E) The $\mathrm{D}_{\text {mean }}$ value was $0.814 \times 10^{-3} \mathrm{~mm} / \mathrm{s}$. (F) The $\mathrm{D}^{*}{ }_{\text {mean }}$ value was $10.6 \times 10^{-2} \mathrm{~mm}^{2} / \mathrm{s}$. (G) The $\mathrm{f}_{\text {mean }}$ value was 0.208 . (H) The high expression of Ki-67 was $85 \%$ (IHC, $\times 400$, EnVision). NPC, nasopharyngeal carcinoma; $\mathrm{BF}$, blood flow; $\mathrm{BF}_{\text {mean }}$, mean $\mathrm{BF} ; \mathrm{BF}_{\max }$, maximum $\mathrm{BF} ; \mathrm{BF}_{\min }$, minimum $\mathrm{BF}$; ADC, apparent diffusion coefficient; $\mathrm{D}_{\text {mean }}$, mean $\mathrm{D} ; \mathrm{D}^{*}$, pseudo diffusion coefficient; $\mathrm{D}^{*}$ mean , mean $\mathrm{D}^{*} ; \mathrm{f}$, perfusion fraction; $\mathrm{f}_{\text {mean }}$, mean $\mathrm{f}$.

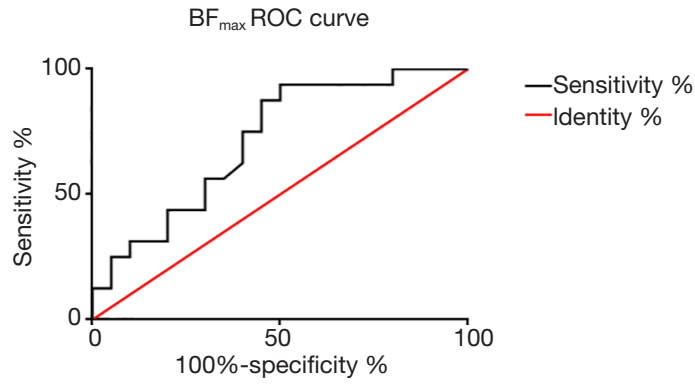

Figure 5 ROC curve for $\mathrm{BF}_{\max }$ in differentiating between low and high Ki-67 statuses in NPC. $\mathrm{BF}_{\max }$, maximum blood flow; ROC, receiver operating characteristic; NPC, nasopharyngeal carcinoma.

prognosis. In a study of NPC, Zhao et al. (7) reported that the cutoff point of high Ki-67 expression was $77.5 \%$, and high Ki-67 expression had a poor prognosis. However, due to the small sample size in our study, there were only 3 cases of $\mathrm{Ki}-67>77.5 \%$, so $77.5 \%$ was not used as the cutoff point for grouping.

Our study is still in the preliminary stage, and there were some limitations. First, there were too few cases for Ki67 immunohistochemistry, which might have impacted the results of the study. Future studies should include a larger sample size to further illustrate the correlation between Ki67, ASL, and IVIM parameters. Second, the ASL scanning sequence in this study was only set with a PLD of $1,025 \mathrm{~ms}$, and a further control study is needed to determine whether this time point was optimal. Third, the $\mathrm{Ki}-67$ value was detected by not taking the corresponding position of $\mathrm{BF}_{\max }$, and the corresponding relationship between them requires further study. Additionally, follow-up for NPC after treatment is still needed to determine the cutoff point of the Ki-67 group and to further clarify the effect of ASL, IVIM, and $\mathrm{Ki}-67$ on prognosis. 
Overall, 3D pCASL and IVIM, as noninvasive functional MR perfusion imaging techniques, can evaluate the perfusion information of NPC. ASL can better evaluate the degree of tumor proliferation than can IVIM, which is beneficial for evaluating the prognosis of patients and aids in clinical treatment by reducing the risk of recurrence and metastasis. Our results also suggest that the $\mathrm{BF}_{\max }$ parameter has the most utility in distinguishing between high and low Ki-67 levels.

\section{Acknowledgments}

This study was supported by Jingquan Yang and Xiao hong He from the Department of Radiology, The First People's Hospital of Foshan, Foshan, China.

Funding: None.

\section{Footnote}

Conflicts of Interest: All authors have completed the ICMJE uniform disclosure form (available at http://dx.doi. org/10.21037/qims-20-349). The authors have no conflicts of interest to declare.

Ethical Statement: The study was approved by the institutional review board and the ethical review office of The First People's Hospital of Foshan [no.L (2019) 8th; the registration number of the ethics board]. Written informed consent was obtained from the patients for publication of this study and any accompanying images. A copy of the written consent is available for review by the editor-in-chief of this journal.

Open Access Statement: This is an Open Access article distributed in accordance with the Creative Commons Attribution-NonCommercial-NoDerivs 4.0 International License (CC BY-NC-ND 4.0), which permits the noncommercial replication and distribution of the article with the strict proviso that no changes or edits are made and the original work is properly cited (including links to both the formal publication through the relevant DOI and the license). See: https://creativecommons.org/licenses/by-nc-nd/4.0/.

\section{References}

1. Jemal A, Bray F, Center MM, Ferlay J, Ward E, Forman D. Global cancer statistics. CA Cancer J Clin 2011;61:69-90.

2. Zhang L, Chen QY, Liu H, Tang LQ, Mai HQ. Emerging treatment options for nasopharyngeal carcinoma. Drug Des Devel Ther 2013;7:37-52.

3. Airoldi M, Garzaro M, Valente G, Mamo C, Bena A, Giordano C, Pecorari G, Gabriele P, Gabriele AM, Beatrice F. Clinical and biological prognostic factors in 179 cases with sinonasal carcinoma treated in the Italian Piedmont region. Oncology 2009;76:262-9.

4. Ahn HK, Jung M, Ha SY, Lee JI, Park I, Kim YS, Hong J, Sym SJ, Park J, Shin DB, Lee JH, Cho EK. Clinical significance of Ki-67 and p53 expression in curatively resected non-small cell lung cancer. Tumour Biol 2014;35:5735-40.

5. Luporsi E, Andre F, Spyratos F, Martin PM, Jacquemier J, Penault-Llorca F, Tubiana-Mathieu N, Sigal-Zafrani B, Arnould L, Gompel A, Egele C, Poulet B, Clough KB, Crouet H, Fourquet A, Lefranc JP, Mathelin C, Rouyer N, Serin D, Spielmann M, Haugh M, Chenard MP, Brain E, De Cremoux P, Bellocq JP. Ki-67: level of evidence and methodological considerations for its role in the clinical management of breast cancer: Analytical and critical review. Breast Cancer Res Treat 2012;132:895-915.

6. Zhao Y, Shen L, Huang X, Jing D, Huang D, Fu J, Li Z, Zhang G, Shen L. High expression of Ki-67 acts a poor prognosis indicator in locally advanced nasopharyngeal carcinoma. Biochem Biophys Res Commun 2017;494:390-6.

7. Zhao L, Chen H, Hu B, Zhang H, Lin Q. Prognostic significance of Ki67 expression and the derived neutrophillymphocyte ratio in nasopharyngeal carcinoma. Cancer Manag Res 2018;10:1919-26.

8. Xiao Z, Zhong Y, Tang Z, Qiang J, Qian W, Wang R, Wang J, Wu L, Tang W, Zhang Z. Standard diffusionweighted, diffusion kurtosis and intravoxel incoherent motion MR imaging of sinonasal malignancies: correlations with Ki-67 proliferation status. Eur Radiol 2018;28:2923-33.

9. Qiu X, Wang H, Wang Z, Fu Y, Yin J. Expression of PCNA, Ki-67 and COX-2 in breast cancer based on DCE-MRI image information. J Infect Public Health 2020;13:2032-7.

10. Zeng Q, Jiang B, Shi F, Ling C, Dong F, Zhang J. 3D pseudocontinuous arterial spin-labeling MR imaging in the preoperative evaluation of gliomas. Am J Neuroradiol 2017;38:1876-83.

11. Ma W, Ji Y, Qi L, Guo X, Jian X, Liu P. Breast cancer Ki67 expression prediction by DCE-MRI radiomics features. Clin Radiol 2018;73:909.e1-5.

12. Takahashi H, Ishii K, Hosokawa C, Hyodo T, Kashiwagi N, 
Matsuki M, Ashikaga R, Murakami T. Clinical application of 3D arterial spin-labeled brain perfusion imaging for Alzheimer disease: comparison with brain perfusion SPECT. AJNR Am J Neuroradiol 2014;35:906-11.

13. Roy B, Awasthi R, Bindal A, Sahoo P, Kumar R, Behari S, Ojha BK, Husain N, Pandey CM, Rathore RK, Gupta RK. Comparative evaluation of 3-dimensional pseudocontinuous arterial spin labeling with dynamic contrast-enhanced perfusion magnetic resonance imaging in grading of human glioma. J Comput Assist Tomogr 2013;37:321-6.

14. Lin M, Yu X, Ouyang H, Luo D, Zhou C. Consistency of T2WI-FS/ASL fusion images in delineating the volume of nasopharyngeal carcinoma. Sci Rep 2015;5:18431.

15. Lin M, Yu X, Luo D, Ouyang H, Xie L, Wu B, Zhou C. Investigating the correlation of arterial spin labeling and dynamic contrast enhanced perfusion in primary tumor of nasopharyngeal carcinoma. Eur J Radiol 2018;108:222-9.

16. Le Bihan D, Breton E, Lallemand D, Aubin ML, Vignaud J, Laval-Jeantet M. Separation of diffusion and perfusion in intravoxel incoherent motion MR imaging. Radiology 1988;168:497-505.

17. Li T, Che-Nordin N, Wáng YXJ, Rong PF, Qiu SW, Zhang SW, Zhang P, Jiang YF, Chevallier O, Zhao F, Xiao $\mathrm{XY}$, Wang $\mathrm{W}$. Intravoxel incoherent motion derived liver perfusion/diffusion readouts can be reliable biomarker for the detection of viral hepatitis B induced liver fibrosis. Quant Imaging Med Surg 2019;9:371-85.

18. Wáng YXJ. bLiving tissue intravoxel incoherent motion (IVIM) diffusion MR analysis without $=0$ image: An example for liver fibrosis evaluation. Quant Imaging Med Surg 2019;9:127-33.

19. Lai V, Li X, Lee VH, Lam KO, Fong DY, Huang B, Chan Q, Khong PL. Nasopharyngeal carcinoma: comparison of diffusion and perfusion characteristics between different tumour stages using intravoxel incoherent motion MR imaging. Eur Radiol 2014;24:176-83.

20. Xiao-ping $Y$, Jing H, Fei-ping L, Yin H, Qiang L, Lanlan W, Wei W. Intravoxel incoherent motion MRI for predicting early response to induction chemotherapy and chemoradiotherapy in patients with nasopharyngeal carcinoma. J Magn Reson Imaging 2016;43:1179-90.

21. Xiao Y, Chen Y, Chen Y, He Z, Yao Y, Pan J. Longitudinal assessment of intravoxel incoherent motion diffusion weighted imaging in evaluating the radio-sensitivity of nasopharyngeal carcinoma treated with intensitymodulated radiation therapy. Cancer Res Treat 2019;51:345-56.
22. Mao J, Shen J, Yang Q, Yu T, Duan X, Zhong J, Phuyal P, Liang B. Intravoxel incoherent motion MRI in differentiation between recurrent carcinoma and postchemoradiation fibrosis of the skull base in patients with nasopharyngeal carcinoma. J Magn Reson Imaging 2016;44:1556-64.

23. Kim Y, Ko K, Kim D, Min C, Kim SG, Joo J, Park $B$. Intravoxel incoherent motion diffusion-weighted MR imaging of breast cancer: Association with histopathological features and subtypes. Br J Radiol 2016;89:20160140.

24. Cui Y, Zhang C, Li X, Liu H, Yin B, Xu T, Zhang Y, Wang D. Intravoxel incoherent motion diffusion-weighted magnetic resonance imaging for monitoring the early response to ZD6474 from nasopharyngeal carcinoma in nude mouse. Sci Rep 2015;5:16389.

25. Shen N, Zhao L, Jiang J, Jiang R, Su C, Zhang S, Tang X, Zhu W. Intravoxel incoherent motion diffusion-weighted imaging analysis of diffusion and microperfusion in grading gliomas and comparison with arterial spin labeling for evaluation of tumor perfusion. J Magn Reson Imaging 2016;44:620-32.

26. Ren T, Wen CL, Chen LH, Xie SS, Cheng Y, Fu YX, Oesingmann N, De Oliveira A, Zuo PL, Yin JZ, Xia S, Shen $W$. Evaluation of renal allografts function early after transplantation using intravoxel incoherent motion and arterial spin labeling MRI. Magn Reson Imaging 2016;34:908-14.

27. Alsop DC, Detre JA, Golay X, Günther M, Hendrikse J, Hernandez-Garcia L, Lu H, MacIntosh BJ, Parkes LM, Smits M, van Osch MJ, Wang DJ, Wong EC, Zaharchuk G. Recommended implementation of arterial spin-labeled perfusion MRI for clinical applications: A consensus of the ISMRM perfusion study group and the European consortium for ASL indementia, Magn Reson Med 2015;73:102-16.

28. Fudaba H, Shimomura T, Abe T, Matsuta H, Momii Y, Sugita K, Ooba H, Kamida T, Hikawa T, Fujiki M. Comparison of multiple parameters obtained on $3 \mathrm{~T}$ pulsed arterial spin-labeling, diffusion tensor imaging, and MRS and the Ki-67 labeling index in evaluating glioma grading. AJNR Am J Neuroradiol 2014;35:2091-8.

29. Fujima N, Kudo K, Tsukahara A, Yoshida D, Sakashita T, Homma A, Tha KK, Shirato H. Measurement of tumor blood flow in head and neck squamous cell carcinoma by pseudo-continuous arterial spin labeling: comparison with dynamic contrast-enhanced MRI. J Magn Reson Imaging 2015;41:983-91. 
30. Abdel Razek AAK, Nada N. Arterial spin labeling perfusion-weighted MR imaging: correlation of tumor blood flow with pathological degree of tumor differentiation, clinical stage and nodal metastasis of head and neck squamous cell carcinoma. Eur Arch Otorhinolaryngol 2018;275:1301-7.

31. Lanzman RS, Robson PM, Sun MR, Patel AD, Mentore K, Wagner AA, Genega EM, Rofsky NM, Alsop DC, Pedrosa I. Arterial spin-labeling MR imaging of renal masses: correlation with histopathologic findings. Radiology 2012;265:799-808.

32. Evans SM, Judy KD, Dunphy I, Jenkins WT, Hwang W'T, Nelson PT, Lustig RA, Jenkins K, Magarelli DP, Hahn SM, Collins RA, Grady MS, Koch CJ. Hypoxia is important in the biology and aggression of human glial brain tumors. Clin Cancer Res 2004;10:8177-84.

33. Mashiko R, Takano S, Ishikawa E, Yamamoto T, Nakai K, Matsumura A. Hypoxia-inducible factor 1alpha expression is a prognostic biomarker in patients with astrocytic tumors associated with necrosis on MR image. J Neurooncol 2011;102:43-50.

34. Shin JK, Kim JY. Dynamic contrast-enhanced and diffusion-weighted MRI of estrogen receptor-positive invasive breast cancers: Associations between quantitative MR parameters and Ki-67 proliferation status. J Magn Reson Imaging 2017;45:94-102.

Cite this article as: $\mathrm{Wu} \mathrm{W}$, Jiang G, Xu Z, Wang R, Pan A, Gao M, Yu T, Huang L, Quan Q, Li J. Three-dimensional pulsed continuous arterial spin labeling and intravoxel incoherent motion imaging of nasopharyngeal carcinoma: correlations with Ki-67 proliferation status. Quant Imaging Med Surg 2021;11(4):1394-1405. doi: 10.21037/qims-20-349
35. Huang $\mathrm{Y}$, Lin $\mathrm{Y}, \mathrm{Hu} \mathrm{W}, \mathrm{Ma} \mathrm{C}$, Lin W, Wang Z, Liang J, Ye W, Zhao J, Wu R. Diffusion kurtosis at 3.0T as an in vivo imaging marker for breast cancer characterization: correlation with prognostic factors. J Magn Reson Imaging 2019;49:845-56.

36. De Felice C, Cipolla V, Guerrieri D, Santucci D, Musella A, Porfiri LM, Meggiorini ML. Apparent diffusion coefficient on 3.0 Tesla magnetic resonance imaging and prognostic factors in breast cancer. Eur J Gynaecol Oncol 2014;35:408-14.

37. Molinari C, Clauser P, Girometti R, Linda A, Cimino E, Puglisi F, Zuiani C, Bazzocchi M. MR mammography using diffusion-weighted imaging in evaluating breast cancer: A correlation with proliferation index. Radiol Med 2015;120:911-8.

38. Valente G, Mamo C, Bena A, Prudente E, Cavaliere C, Kerim S, Nicotra G, Comino A, Palestro G, Isidoro C, Beatrice F. Prognostic significance of microvessel density and vascular endothelial growth factor expression in sinonasal carcinomas. Hum Pathol 2006;37:391-400.

39. Lin Y, Li J, Zhang Z, Xu Q, Zhou Z, Zhang Z, Zhang Y, Zhang Z. Comparison of intravoxel incoherent motion diffusion-weighted MR imaging and arterial spin labeling MR imaging in gliomas. Biomed Res Int 2015;2015:234245. 